JOURNAL OF

SYNCHROTRON

RADIATION

ISSN 1600-5775

Received 17 October 2018

Accepted 27 February 2019

Edited by R. W. Strange, University of Essex, UK

₹ Joint first authors.

§ Present address: CLS@APS Sector 20,

Advanced Photon Source, Argonne National

Laboratory, 9700 South Cass Avenue, Argonne,

IL 60439, USA.

- Present address: Alba Synchrotron, Carrer de la Llum 2-26, 08290 Cerdanyola del Vallès,

Spain.

Keywords: fluorescence mode; multi-technique characterization; in situ characterization; coupled experiments; XAS-DRIFTS-MS.

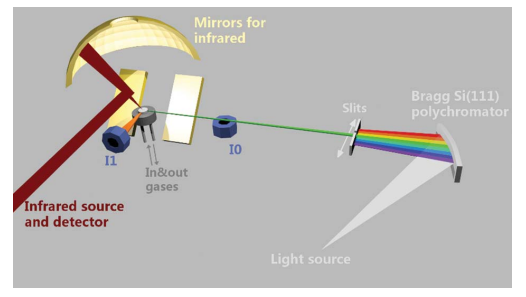

OPEN $\odot$ ACCESS

\section{A flexible cell for in situ combined XAS-DRIFTS- MS experiments}

\author{
Debora M. Meira, ${ }^{\mathrm{a} *} \ddagger \S$ Manuel Monte, ${ }^{\mathrm{a} *} \neq$ Marcos Fernández-García, \\ Frederic Meunier, ${ }^{\mathrm{c}}$ Olivier Mathon, ${ }^{\mathrm{a}}$ Sakura Pascarelli ${ }^{\mathrm{a}}$ and Giovanni Agostini ${ }^{\mathrm{a}} \boldsymbol{}$
}

\begin{abstract}
${ }^{\mathbf{a}}$ European Synchrotron Radiation Facility (ESRF), Avenue des Martyrs 71, 38000 Grenoble, France, ${ }^{\mathbf{b}}$ Instituto de Catálisis y Petroleoquimica (ICP-CSIC), C/Marie Curie 2, Cantoblanco, 28049 Madrid, Spain, and Institut de Recherches sur la Catalyse et l'Environnement de Lyon, Université de Lyon 1, CNRS, Avenue Albert Einstein 2, 69626 Villeurbanne, France. *Correspondence e-mail: dmeira@anl.gov, manuel.monte@esrf.fr
\end{abstract}

A new cell for in situ combined X-ray absorption, diffuse reflectance IR Fourier transform and mass spectroscopies (XAS-DRIFTS-MS) is presented. The cell stands out among others for its achievements and flexibility. It is possible to perform XAS measurements in transmission or fluorescence modes, and the cell is compatible with external devices like UV-light and Raman probes. It includes different sample holders compatible with the different XAS detection modes, different sample forms (free powder or self-supporting pellet) and different sample loading/total absorption. Additionally, it has a small dead volume and can operate over a wide range of temperature (up to $600^{\circ} \mathrm{C}$ ) and pressure (up to 5 bar). Three research examples will be shown to illustrate the versatility of the cell. This cell covers a wider range of applications than any other cell currently known for this type of study.

\section{Introduction}

Heterogeneous catalysis is one of the most important branches of applied chemistry (Friend \& Xu, 2017). Nowadays, most industrial products (from chemicals to energy) require the use of catalysts at some point in the process. Moreover, the trend towards zero-emission operations cannot be achieved without them. Among catalysts, nanoparticles out-perform bulk materials as their smaller size gives a higher exposed surface and a higher concentration of active sites. However, the study of these catalysts is especially difficult because of their properties: they are unstable, highly reactive and change constantly depending on the ambient conditions (temperature, pressure, humidity, chemicals or ions in contact, method of synthesis, interaction with the support etc.). As the properties (structure, stability and reactivity) of the intermediates created under reaction conditions are of great importance to elucidate the mechanism of a reaction (Simpson \& RodríguezLópez, 2015), the study of a catalyst under real operating conditions is of the utmost importance (Dou et al., 2017).

To elucidate the structure and reactivity of nanoparticles and the origin of their performance, it is necessary to understand their properties at the atomic level. Only after this can a rational design enhance their performance. To achieve this goal, in situ and operando characterization experiments are very important and nowadays are very common. However, no single technique can provide a full picture of a process; on the contrary, each one gives information on different aspects or at different scales and they can complement each other. To understand a catalytic process, the reactivity of the catalyst, its changes during the reaction or its behaviour under different 
conditions, the use of several techniques (the more the better!) becomes mandatory (Baer et al., 2013). Nevertheless, performing each characterization technique at different times with different equipment and setups, in addition to the time taken, also implies differences in the process and one is thus studying slightly different, not equivalent, materials or conditions. The multi-technique approach is an attempt to overcome this drawback. In this sense, the combination of $\mathrm{X}$-ray absorption, diffuse reflectance IR Fourier transform and mass spectroscopies (XAS, DRIFTS and MS) covers a significant range of properties and behaviours of interest in the solid-gas-phase heterogeneous catalytic cycle. XAS can provide information about the electronic and geometric structure of the metallic centre (e.g. oxidation state, geometry and neighbours of the metal centre) (Sun et al., 2015; Kuzmin \& Chaboy, 2014; Frenkel et al., 2001), while DRIFTS can follow the presence and evolution of bonds between specific atoms, thus aiding the understanding of the existence of specific adsorbents (Armaroli et al., 2004; Meunier, 2016; Sirita et al., 2007). Finally, MS allows understanding of changes in the gas phase and, consequently, the activity of the catalyst. Fig. 1 illustrates this cycle.

More than ten years ago, Newton and co-workers (Newton et al., 2004, 2007) designed a combined XAS, DRIFTS and MS experiment on beamline ID24 at the ESRF. With this cell, fast gas switching was possible, but the temperature was limited $\left(400^{\circ} \mathrm{C}\right)$ and the cell presented a bypass of the gas feed in the catalytic bed. Later, a commercial cell from SpectraTech was modified (Newton, 2009) but, in addition to a larger dead volume compared with the previous cell, the issue with the bypass was not completely solved (Meunier et al., 2007, 2008). Meanwhile, other cells were also developed elsewhere (Marinkovic et al., 2011; Beyer et al., 2014; Yao et al., 2014; Marchionni et al., 2017), but we will keep our attention on the cells developed for ID24.

Recently, Agostini et al. (2018) presented a new design overcoming some limitations of the previous versions. In

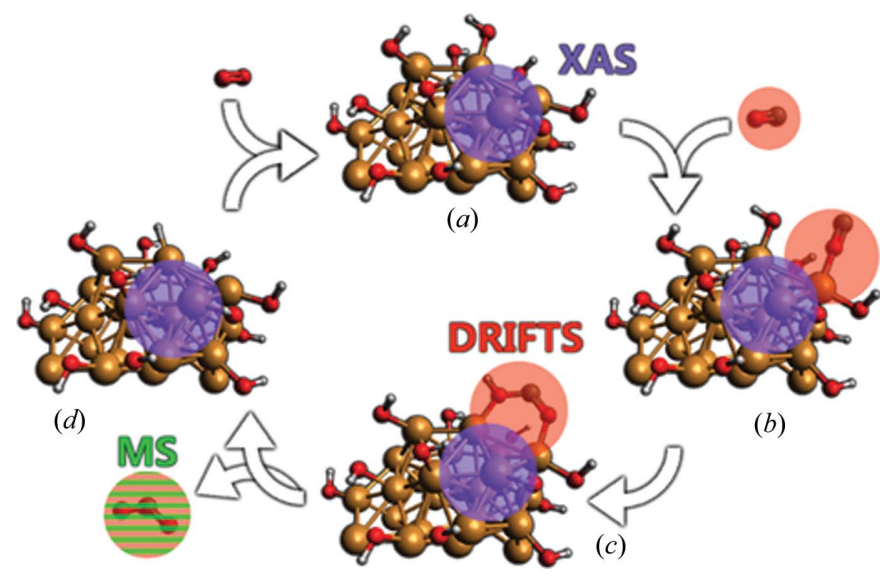

Figure 1

A schematic diagram of the catalytic cycle aspects studied by each technique. (a) The initial state of the catalyst. (b) Adsorption of a molecule. (c) The intermediate stage in which the adsorbed molecule reacts with an atom at the surface of the catalyst. (d) A new molecule has left the catalyst, becoming an intermediate and/or product. particular, measurements at high temperatures (up to $600^{\circ} \mathrm{C}$ ) and with a small dead volume became possible in transmission mode. However, this configuration requires the fulfilment of quite restrictive requirements in terms of minimum metal loading and maximum total absorption values, severely limiting the number of catalysis systems that can be investigated. Indeed, catalysts often constitute dilute materials on top of a heavy matrix, where XAS measurements have to be conducted in fluorescence mode.

Thus, to overcome these limitations we have improved the design of this cell (Agostini et al., 2018) to perform coupled experiments using XAS, DRIFTS and MS, particularly on highly dilute materials and/or heavy matrices where XAS measurements in fluorescence mode are necessary.

\section{The cell}

The combined XAS-DRIFTS system is composed of a commercial Varian 680 FT-IR instrument, a set of Au-coated mirrors and a diffuse reflectance sphere provided by OMT Solutions. IR radiation impinges on the sample after reflection by the mirrors. The same mirrors reflect the backscattered light towards an MCT (mercury cadmium telluride) external detector after passing through a beam splitter. A set of massflow controllers are used to handle the gases according to experimental requirements.

The cell is based on the previous version (Agostini et al., 2018) developed on beamline ID24 at the ESRF. This previous version of the cell [shown schematically in Fig. 2(a)] was optimized to perform time-resolved experiments only in the transmission configuration, with a horizontal beam size smaller than $1 \mathrm{~mm}$. As with the previous one, the cell described here can be heated to $600^{\circ} \mathrm{C}$, the gases are preheated before interacting with the sample and the cell can sustain up to 5 bar $(1 \mathrm{bar}=100000 \mathrm{~Pa})$. The current design has been modified to make it more versatile, to overcome some limitations and to make it easier to work with. The novelty of this cell compared with the previous one is the possibility of performing XAS measurements in fluorescence mode, at the same time keeping the possibility of measurements in the transmission configuration [Figs. 2(b) and 2(c)]. The exchange between the two configurations is very fast and easy, requiring just a change of sample holder as explained below. As with the previous version, this cell can be hosted on any XAS beamline equipped for operando studies of catalysts, with the benefit of performing the measurements in fluorescence mode (Castillejos-López et al., 2017). As before, the cell alignment is independent for DRIFTS and XAS to maximize the quality of both measurements. Before each measurement, the IR signal is maximized by moving the cell vertically to place the sample surface at the focal point of the reflectance sphere. After that, to ensure that both techniques will measure the same region of the sample, a motorized table performs a vertical scan of the whole setup, and the beam is positioned as close as possible to the sample surface. Additionally, it is compatible with other equipment such as light sources (e.g. for photocatalysis) or Raman probes. These characteristics make 

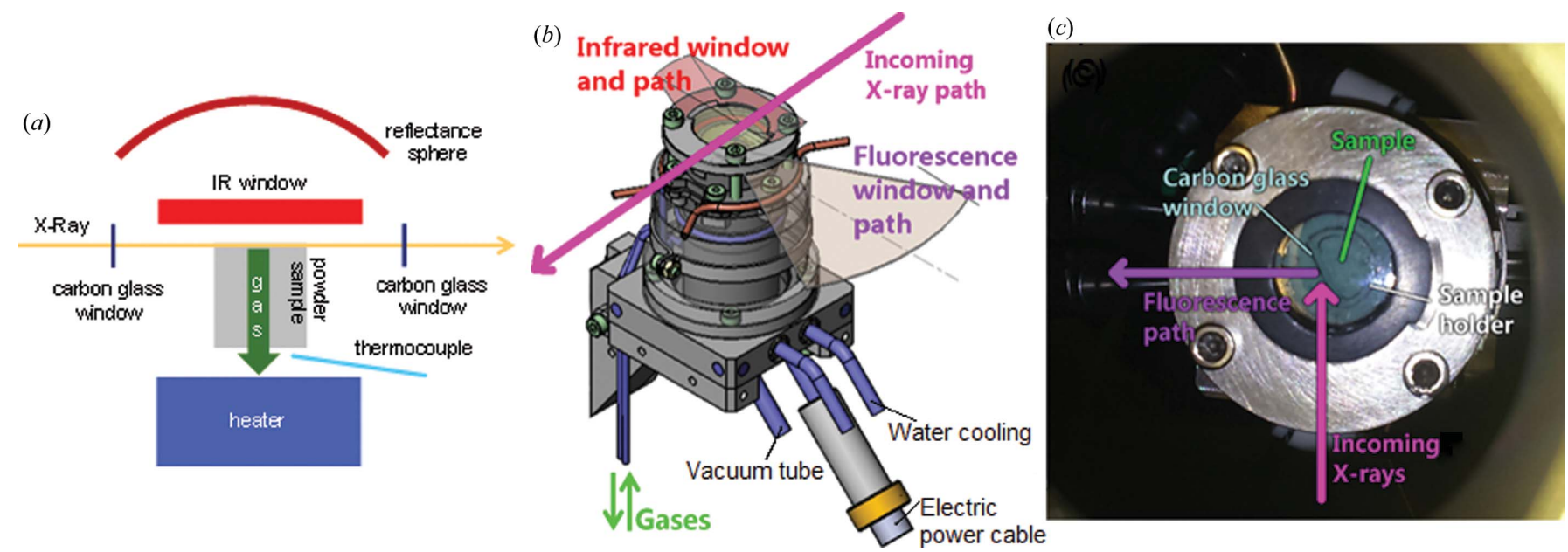

Figure 2

(a) A schematic diagram of the first version of the cell, taken from Agostini et al. (2018). (b) A drawing of the cell and (c) a photograph of the cell from above, with the fluorescence sample holder. The cell has two windows in the path of the X-ray beam for transmission measurements. A third window on one side allows the fluorescence to leave the cell. In fluorescence measurements, the sample is placed in a holder at $45^{\circ}$ with respect to the incoming and outgoing X-ray beams. Additionally, the cell is equipped with pipes for gases (in and out) and internal heating.

our cell of wider usability than other DRIFTS-fluorescence XAS cells reported previously (Yao et al., 2014).

Powder samples are ideal for catalytic applications. Using the sample in powder form, rather than in pellet form, enables catalytic results from in situ experiments carried out at the synchrotron to be compared with the results of experiments performed earlier elsewhere. However, when DRIFTS spectra are not needed, a pellet sample could be a better option from the point of view of XAS, due to the homogeneity of the sample (Grunwaldt et al., 2004). Even in this case, the small dead volume of the cell still makes it of great use.

Additionally, transmission XAS requires different sample thicknesses depending on the system (metal loading and energy), while in fluorescence XAS the available solid angle is often the most crucial parameter.

Therefore, we designed two new sample holders [Figs. 3(a) and $3(c)$ ] in addition to the ones with increasing path length (from 1 to $5 \mathrm{~mm}$ ) developed for the previous version of the cell [Fig. 3(b)]. The first one is dedicated to measurements using pellets [Fig. 3(a)] and the second one for powders to work in fluorescence XAS [with an output window of $9 \times$ $4 \mathrm{~mm}$, Figs. 3(c) and 3(d)].

In the pellet sample holder [Fig. 3(a)], two screws hold small plates to keep the pellet perpendicular to the incoming X-ray beam. In the fluorescence sample holder, for powder samples [Fig. 3(c)], the X-rays arrive at and leave the sample through a carbon glass window, the thickness of which can be selected according to the working energy to reduce total absorption (down to $60 \mu \mathrm{m}$ ) or maximize its resistance (up to $500 \mu \mathrm{m}$ ).

Differing from the previous version, the top part of the cell is split into two parts (the so-called dome and lid, see Fig. 4), which makes it unnecessary to dismount everything to change the sample. When needed, four screws allow the lid to be removed and the sample holder to be accessed. This, together with the design of the joints, reduces the possibility of leaks and makes this process easier. This solution is very useful in order to optimize maintenance and repair time, since the cell is used at a user facility and experiments are performed continuously. Although the cell presents a small dead volume $\left(\sim 2 \mathrm{~cm}^{3}\right)$, because of the removable lid it is bigger than the previous version of the cell where the IR window was glued $\left(0.5 \mathrm{~cm}^{3}\right)$. The dome has three windows specifically for XAS, two in front of each other and another one at $90^{\circ}$. The first two are used for transmission measurements, for the incoming and outgoing X-rays, and they are quite small $(3 \times 2 \mathrm{~mm})$. The third one is much larger $(9 \times 4 \mathrm{~mm})$ in order to guarantee a wide solid angle for fluorescence measurements. All three

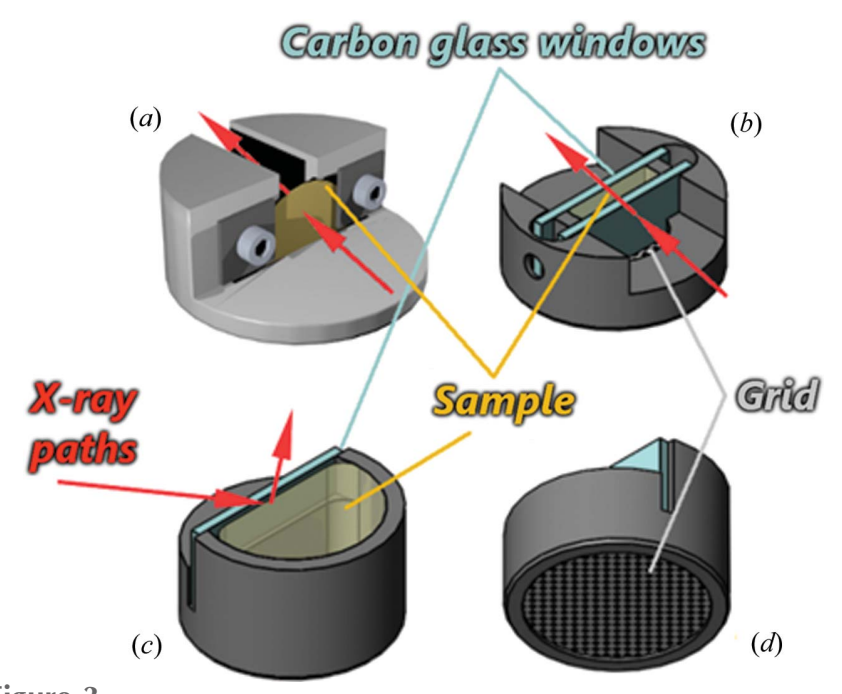

Figure 3

Some of the sample holders available. Transmission sample holders for $(a)$ a pellet and $(b)$ a powder with $1 \mathrm{~mm}$ sample thickness. $(c),(d)$ The fluorescence sample holder from two different perspectives. Red arrows indicate the X-ray path, both incoming and outgoing. All holders have a grid at the bottom to hold the sample and allow the gases to go through it. The sample (powder) must be packed as compact as possible, graining it before positioning and leaving a nice flat surface to improve recording of IR spectra. 
(a)

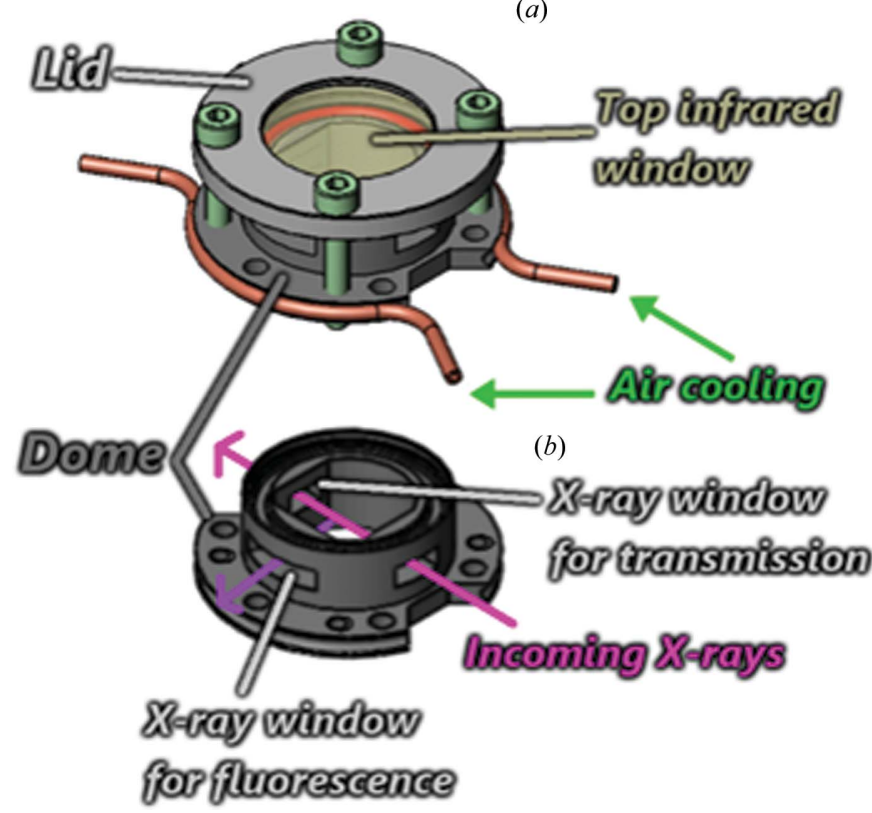

Figure 4

The cell dome, $(a)$ with and $(b)$ without the lid. Four screws [panel $(a)$, in green] allow removal of the lid and access to the sample holder inside the dome. Kapton or carbon glass can form the three windows for X-ray transmission and fluorescence [panel $(b)]$.

windows can be either Kapton foil or carbon glass (thickness up to $500 \mu \mathrm{m}$ ). The former is more transparent to X-rays and thus more desirable, but the latter has a higher thermal stability. With the current design, the Kapton window is stable up to a cell temperature of $500^{\circ} \mathrm{C}$ (the temperature of the window is lower, thanks to the air-cooling around it). In addition to its higher resistance to high temperatures, the carbon glass window (as thin as $60 \mu \mathrm{m}$ ) can hold 5 bar of pressure inside the cell, whereas the Kapton one breaks above 2 bar. The lid of the dome has a circular window of $\mathrm{KBr}$ or $\mathrm{CaF}_{2}(\varnothing 25 \mathrm{~mm}$, thickness $1-4 \mathrm{~mm})$ through which IR light transits from the source to the sample and back to the IR detector. In addition to the IR survey, using a UV quality $\mathrm{CAF}_{2}$ window (Crystran) the top window can be used to illuminate the sample from above for photocatalysis experiments or to simultaneously record a Raman spectrum.

When needed, an Si PIN diode or a Vortex silicon drift detector (SDD) can be placed facing the third window of the dome [Position 1, Figs. 5(a), 5(b) and experimental setup photograph Fig. 5(c)] or facing the window of the dome lid [Position 2, Fig. 5(b) and experimental setup photograph Fig. 5(d)]. A support was designed to hold the SDD vertically [Fig. 5(d)] and move it up and down through a hole in the IR gold reflectance sphere placed on top of the cell. The chosen location will depend on the characteristics of the experiment. The side window (Position 1) is mandatory for low-energy edges, due to the high absorption of the IR window. In addition, placing the detector at Position 1 reduces the elastic scattering contribution. Placing the detector at Position 2 provides a larger solid angle for the detector, but only highenergy edges can be measured. Another drawback of the latter configuration is that the fluorescence detector hides part of the IR signal. Thus, the signal-to-noise ratio decreases for the IR measurements.

The cell has been tested in fluorescence mode with a Vortex SDD and an Si PIN diode, and the results are presented in the next section.

\section{Application examples}

Three examples, which show some of the possible applications of the described cell, are presented in this section. All experiments were performed in fluorescence mode.

In the first one, fast XANES acquisition (turbo-XAS mode) was performed on the dispersive beamline (EDXAS) ID24 at ESRF (Pascarelli et al., 1999; Nagai et al., 2008). The reduction of a $\mathrm{Cu}$ catalyst was monitored under hydrogen and carbon monoxide; in the case of CO reduction, DRIFTS spectra were also taken. $\mathrm{Cu}$ catalysts and reactions involving $\mathrm{CO}$ are very common and this example was chosen to demonstrate the feasibility of this kind of experiment. The $\mathrm{Cu}$ reduction was followed by monitoring the white-line intensity for the XAS measurements and the $\mathrm{CO}$ adsorption band for the IR.

In the second example, XAS measurements, in step-scan mode, were performed using the SDD on top of the IR window. This example involves CoSn catalysts applied to the Fisher-Tropsh reaction that is commercially very important. The use of both techniques in this case helped to elucidate the formation of various phases between the catalyst components and the reaction mechanism, since the adsorbed species on the surface could be monitored.

The third example is a photo-catalytic experiment where the X-ray detector was placed at the side window and the top window was used to illuminate the sample with UV light [Fig. 5(a)]. In this last case, photo-catalytic $\mathrm{Cu}-, \mathrm{Ni}-$ or $\mathrm{CuNi}-$ $\mathrm{TiO}_{2}$ catalysts for hydrogen production through methanol reforming were monitored. A photo-catalytic approach for hydrogen production is very appealing but, at the same time, it constitutes a challenging experiment, since distinguishing the catalytic effects of the reactive atmosphere and light is not straightforward.

\subsection{Time-resolved XANES and DRIFTS measurements: Cu-based catalyst reduction}

In this experiment, a combination of fluorescence XANES, DRIFTS and MS is performed over a powder catalyst to follow the reduction of the active metal. Very fast spectra acquisition over a dilute sample is shown under in situ conditions. Time-resolved XAS measurements for dilute materials at low absorption energies are always a challenge. Although the IR data present poor data quality, since the sample is not optimized for IR measurements, this example shows the importance of simultaneous experiments where we can obtain complementary information.

Coupled EDXAS, DRIFTS and MS measurements were performed on beamline ID24 at the ESRF (Pascarelli et al., 2016). An Si(111) polychromator diffracts the X-rays and 

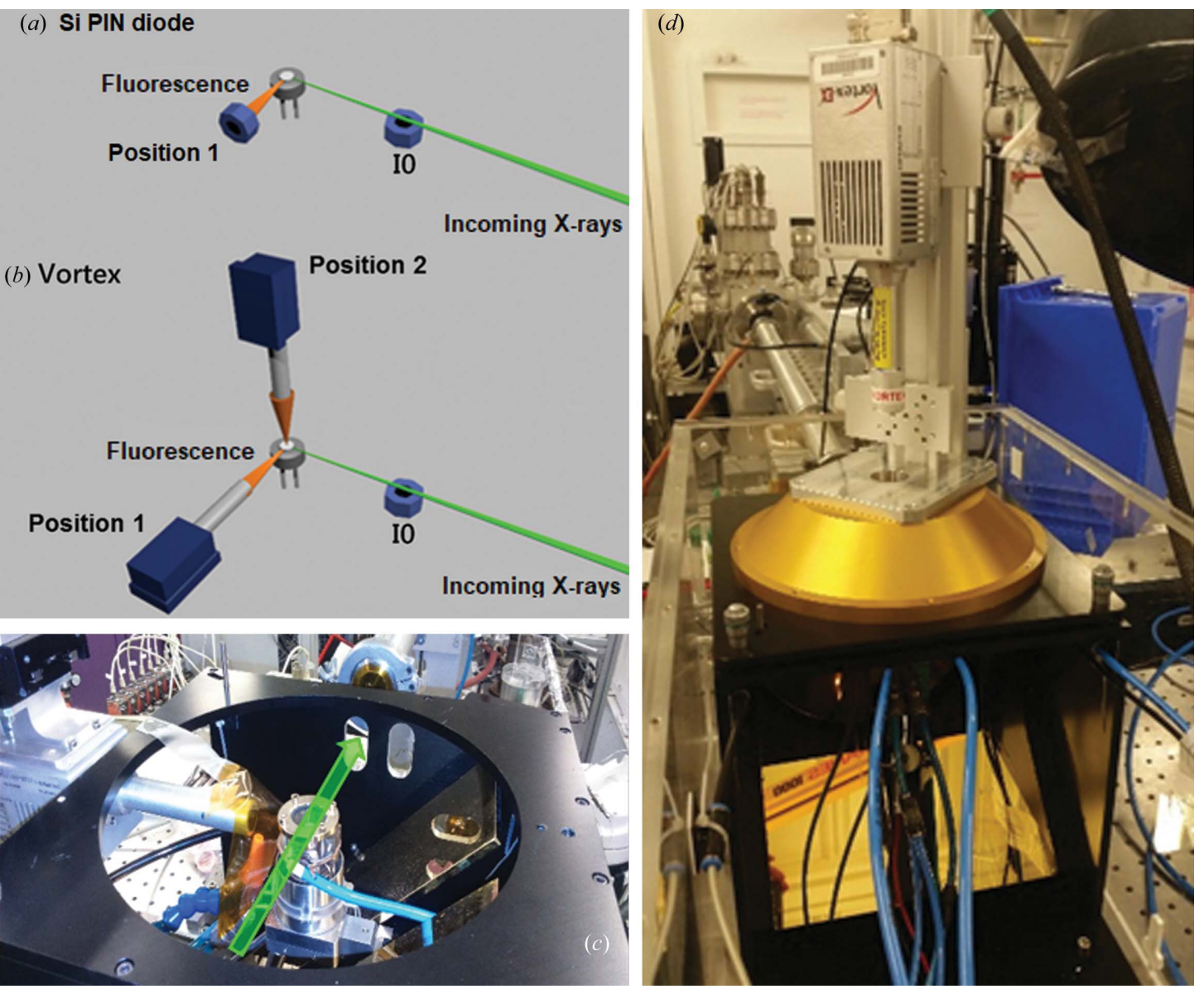

Figure 5

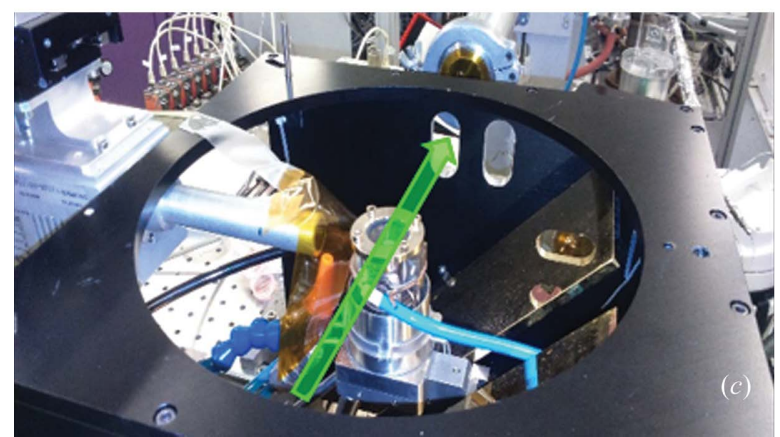

Possibilities for detector position. The fluorescence can be recorded by $(a)$ an Si PIN diode or $(b)$ a Vortex silicon drift detector. Both can be placed either on the horizontal plane, on one side of the sample (Position 1), or vertically (Position 2). (c), (d) Photographs of the experimental setup corresponding to $(c)$ Position 1 and $(d)$ Position 2. In dispersive XAS geometry, $I_{0}$ is recorded by an Si PIN diode placed before the sample, vertically close to the beam path (Pascarelli et al., 1999; Nagai et al., 2008).

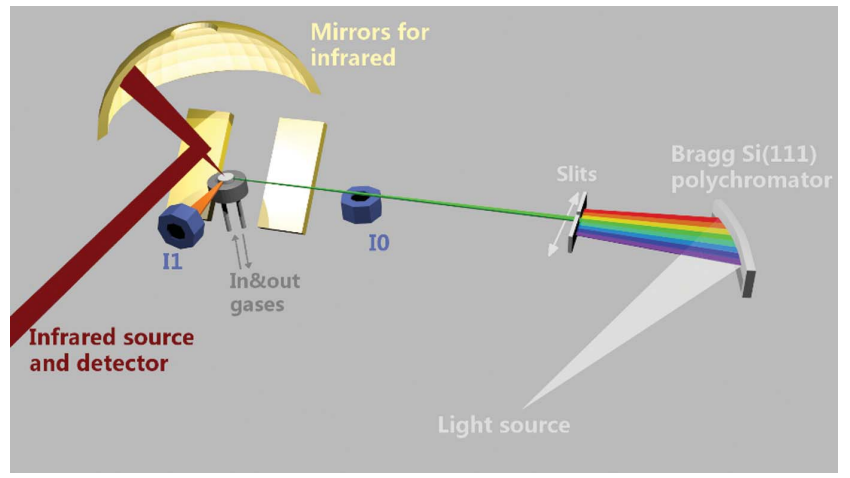

Figure 6

A schematic diagram of the fluorescence EDXAS setup. The pink beam (bottom), after reflection by a set of KB mirrors, arrives at the polychromator (right) and is diffracted with a different angle for each energy. The focal spot of the polychromatic fan of radiation lies in the sample. A pair of slits in the middle of the polychromatic fan selects the energy of X-rays impinging on the sample. An Si PIN diode before the sample measures $I_{0}$ and another on one side of the sample placed at $90^{\circ}$ from the incoming beam detects the fluorescence yield $\left(I_{1}\right)$ for the selected energy. The IR spectra can be measured at the same time: the laser is reflected by the flat inclined mirrors towards the spherical dome and then to the sample; the light which is not absorbed is reflected back following the same path until it reaches a beam splitter, which sends it to the detector. The output gas flow is connected to a mass spectrometer so that chemical reactions involving the gas phase can be followed. focuses them on the sample in the energy range 8860-9520 eV to cover the $\mathrm{Cu} K$ edge. The measurements were performed in turbo-XAS mode (Pascarelli et al., 1999) and the fluorescence was collected using two diodes (one for the incident beam and one to collect the fluorescence coming from the sample, Fig. 6). The acquisition rate for the EDXAS was $12.5 \mathrm{~s}$ per spectrum ( 250 points, $50 \mathrm{~ms}$ per point) while it was $30 \mathrm{~s}$ for the DRIFTS measurements.

The reduction of $1 \mathrm{wt} \% \mathrm{Cu} / \mathrm{SiO}_{2}$ catalyst was performed using 5 vol. $\% \mathrm{H}_{2} / \mathrm{He}\left(20 \mathrm{ml} \mathrm{min}^{-1}\right)$ and 5 vol. $\% \mathrm{CO} / \mathrm{He}$ $\left(20 \mathrm{ml} \mathrm{min}^{-1}\right)$ up to $300^{\circ} \mathrm{C}\left(5^{\circ} \mathrm{C} \mathrm{min}{ }^{-1}\right)$. XANES results were normalized using PyMca (Cotte et al., 2016).

Initially, the copper in the sample is mainly $\mathrm{Cu}^{\mathrm{II}}$, as can be concluded by comparing it with the reference materials $[\mathrm{Cu}$ foil, $\mathrm{Cu}_{2} \mathrm{O}$, $\mathrm{CuO}$; Fig. 7(a)]. As expected, while heating under exposure to either $\mathrm{H}_{2}$ or $\mathrm{CO}$, the adsorption edge of $\mathrm{Cu}$ shifts to higher energy due to an increase of the unoccupied $d$ states of the surface atoms (Kim et al., 2014). However, the spectra do not look like the reference materials $\mathrm{CuO}, \mathrm{Cu}_{2} \mathrm{O}$ or metallic $\mathrm{Cu}$ [Figs. 7(b), 7(c), 7(d)]. These differences could be due to the structure of the copper phase in the sample with respect to the bulk reference materials. For instance, the absence of any pre-edge structure suggests a distorted octahedral coordina- 


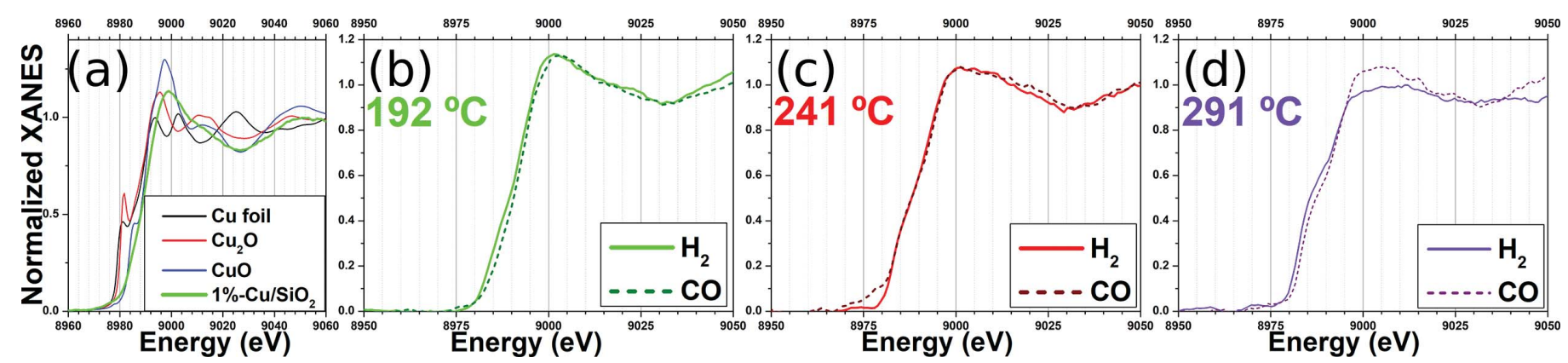

Figure 7

$\mathrm{Cu} K$-edge normalized XANES spectra of the sample $\left(1 \% \mathrm{Cu} / \mathrm{SiO}_{2}\right)(a)$ initially and $(b)-(d)$ during reduction under hydrogen (solid lines) or carbon dioxide (dashed lines) at (b) $192^{\circ} \mathrm{C},(c) 241^{\circ} \mathrm{C}$ and $(d) 291^{\circ} \mathrm{C}$.

tion geometry, as reported for $\mathrm{Cu} / \mathrm{Si}$ and $\mathrm{Cu} / \mathrm{SiAl}$ samples (Gervasini et al., 2006). In addition, the absence of pre-edge features can also be explained by the specific characteristics of the beamline that present, as a limitation for some materials, a strong broadening of the XANES features (Abe et al., 2018).

To show the capabilities of the cell, Fig. 8 illustrates the evolution of the analyte XANES spectra during reduction (temperature ramp of $1^{\circ} \mathrm{C} \mathrm{min}{ }^{-1}$ ). Differences are detected between employing $\mathrm{H}_{2}$ or $\mathrm{CO}$ : changes occur in several steps for the former $\left(175,235\right.$ and $\left.255^{\circ} \mathrm{C}\right)$ but a smoother evolution is observed for the latter (one faint step at $200^{\circ} \mathrm{C}$ ). Principle component analysis shows that three spectra can reproduce the full reduction process in the case of $\mathrm{H}_{2}$ reduction with an accuracy of $99.7 \%$, but only two components are needed to describe the reduction under $\mathrm{CO}$ with an accuracy of $99.9 \%$. This suggests a single reduction step $\mathrm{Cu}^{\mathrm{II}} \rightarrow \mathrm{Cu}^{0}$ with $\mathrm{CO}$, while an intermediate $\mathrm{Cu}^{\mathrm{I}}$ phase appears when $\mathrm{H}_{2}$ is employed. The formation of a $\mathrm{Cu}^{\mathrm{I}}$ intermediate upon reduction of $\mathrm{Cu}^{\mathrm{II}}$ to $\mathrm{Cu}^{0}$ was the subject of debate for years and apparently depends strongly on the system (Cassinelli et al., 2014). The reduction of $\mathrm{CuO}$ to metallic $\mathrm{Cu}$ is reported as a direct process for bulk powders by Kim et al. (2003), whereas for supported catalysts on various supports $\left(\mathrm{Al}_{2} \mathrm{O}_{3}, \mathrm{SiO}_{2}, \mathrm{ZrO}_{2}, \mathrm{ZSM}-5\right.$ etc. $)$ the formation of $\mathrm{Cu}^{\mathrm{I}}$ species is commonly demonstrated by XAS (Muddada et al., 2010; Sato et al., 2012; Ritzkopf et al., 2006; Neylon et al., 2002). Similar to our case, Wang et al. (2004) observed that $\mathrm{CuO}$ started to reduce to metallic $\mathrm{Cu}$ at a temperature of $\sim 200^{\circ} \mathrm{C}$ and was completely transformed to $\mathrm{Cu}^{0}$ at $236^{\circ} \mathrm{C}$. No intermediate phase was seen during the reduction process, in contrast with what was observed under a limited supply of $\mathrm{CO}$ where $\mathrm{Cu}_{2} \mathrm{O}$ was observed. Thus, reduction under $\mathrm{H}_{2}$ started at lower temperatures and led to a more metallic state of copper, while reduction under $\mathrm{CO}$ took longer to start and the $\mathrm{Cu}$ remained in a higher oxidation state.

Under $\mathrm{CO}$, no bands corresponding to the adsorption of $\mathrm{CO}$ were initially observed (room temperature), as the carbonyls of $\mathrm{Cu}^{\mathrm{II}}$ are not stable (Gervasini et al., 2006). On increasing the temperature, two bands stand out in the DRIFTS spectra: $\mathrm{CO}$ stretching of $\mathrm{Cu}^{\mathrm{I}}$ carbonyl around $2125 \mathrm{~cm}^{-1}$ (Dandekar \& Vannice, 1998) and $\mathrm{CO}_{2}$ stretching around $2350 \mathrm{~cm}^{-1}$. The carbonyl band is initially weak but its intensity increases with temperature up to $200^{\circ} \mathrm{C}$ and the centre of the band moves to higher energies, closer to $2130 \mathrm{~cm}^{-1}$, which is usually assigned to CO adsorbed on metallic copper (Xie et al., 2017). Above this temperature the position does not vary any more, but the intensity decreases slightly as the adsorption-desorption equilibrium is shifted (Kwak et al., 2014). Selected DRIFTS spectra are shown in Fig. 9. Although from the XAS results no intermediate of $\mathrm{Cu}^{\mathrm{I}}$ is observed in the reduction process, it is possible to detect the formation of this species in the DRIFTS spectra, an example of the necessity of combining characterization techniques simultaneously. The $\mathrm{CO}$ reduces the

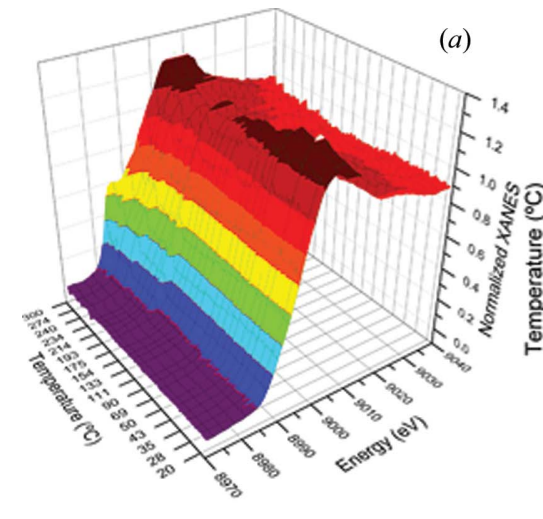

Figure 8

(a) Normalized absorption spectra of the $\mathrm{Cu} K$ edge of the sample $\left(1 \% \mathrm{Cu} / \mathrm{SiO}_{2}\right)$ during reduction under hydrogen. (b), (c) Colour map intensities of the normalized absorption spectra under $(b)$ hydrogen or $(c)$ carbon dioxide.
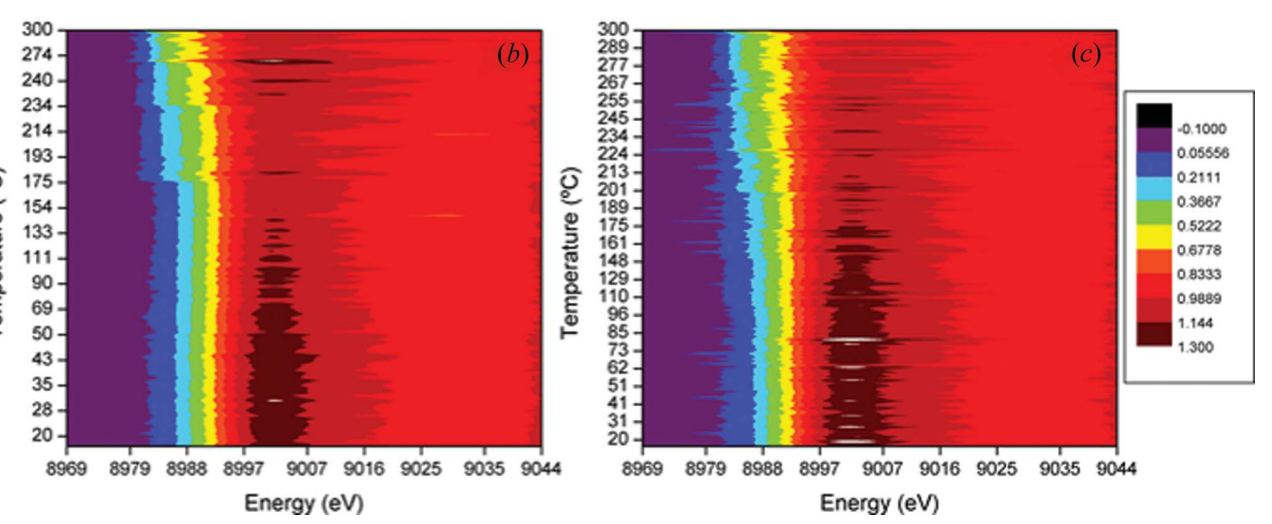
copper, creating $\mathrm{Cu}^{\mathrm{I}}$ carbonyls, but this only happens at the surface of the particles. Inside, the copper is initially $\mathrm{Cu}^{\mathrm{II}}$ and is reduced directly (but progressively) to $\mathrm{Cu}^{0}$, while at the surface $\mathrm{Cu}^{\mathrm{I}}$ dominates for most of the temperature range. Thus, the DRIFTS spectra show a shift between no carbonyl $\rightarrow \mathrm{Cu}^{\mathrm{I}}$ carbonyl $\rightarrow \mathrm{Cu}^{0}$ carbonyl, and the XAS spectra show a shift between $\mathrm{Cu}^{\mathrm{II}}$ and $\mathrm{Cu}^{0}$.

\subsection{High-energy EXAFS combined with DRIFTS and MS: Sn-based catalyst}

In this example, we illustrate the simultaneous recording of EXAFS, DRIFTS and MS under steady-state conditions. In this case, the dilute analytes are investigated with an extended XAS (EXAFS) instead of the time-resolved evolution of XANES as in the previous example.

XAS experiments were performed monitoring the Sn $K$ edge $(29200 \mathrm{eV})$ on beamline BM23 at the ESRF (Mathon et al., 2015) using an $\mathrm{Si}(311)$ double-crystal monochromator. Harmonic rejection was obtained using two Pt mirrors. The measurements were performed in fluorescence mode using a Vortex SDD coupled to FalconX1 electronics (XIA). The detector was placed on top of the IR window $\left(\mathrm{CaF}_{2}, 2 \mathrm{~mm}\right.$ thickness) [Position 2, Fig. 5(b)]. As mentioned before, this geometry improves the detector solid angle, although the fluorescence detector hides part of the IR signal. Thus, the signal-to-noise ratio decreases for the IR measurements.

$\gamma$-Alumina-supported $\mathrm{Co}$ and $\mathrm{Co}-\mathrm{Sn}$ catalysts with different Sn:Co ratios $(1: 120 ; 1: 60 ; 1: 30)$ were measured. Sn was added to act as a poison and possibly reveal the nature of the cobalt active sites involved in the formation of hydrocarbons. The reduction was performed using $\mathrm{H}_{2}\left(40 \mathrm{ml} \mathrm{min}{ }^{-1}\right)$ up to $450^{\circ} \mathrm{C}\left(10^{\circ} \mathrm{C} \mathrm{min}^{-1}\right)$ for $1 \mathrm{~h}$. The temperature was then lowered to $220^{\circ} \mathrm{C}$, where the EXAFS spectra were collected. Afterwards, the sample was exposed to a $30 \mathrm{vol} \% \mathrm{CO} /$ 60 vol. $\% \mathrm{H}_{2} / 10$ vol. $\% \mathrm{He}$ mixture at $220^{\circ} \mathrm{C}$ and EXAFS was measured.
Table 1

Structural parameters obtained from EXAFS spectra, under $\mathrm{H}_{2}$ and under reaction $\left(220^{\circ} \mathrm{C}\right)$.

\begin{tabular}{|c|c|c|c|c|c|c|}
\hline \multirow[b]{2}{*}{ Contributions } & \multicolumn{2}{|l|}{$\mathrm{Sn}-\mathrm{O}$} & \multicolumn{2}{|c|}{$\mathrm{Sn}-\mathrm{O}-\mathrm{Sn}$} & \multicolumn{2}{|c|}{$\mathrm{Sn}-\mathrm{Co}$} \\
\hline & $N$ & $R(\AA)$ & $N$ & $R(\AA)$ & $N$ & $R(\AA)$ \\
\hline Co120Sn_red & $3.8(4)$ & $2.03(3)$ & & & $0.9(9)$ & $2.67(5$ \\
\hline Co12 & 3.4( & 2.05 & $1.0(4)$ & $2.29(1)$ & & \\
\hline Co60 & 3.3( & 2.05 & & & & $2.80(7)$ \\
\hline \multirow[t]{2}{*}{ Co60Sn_reac } & 3.2 & 2.04 & & & $0.4(3)$ & $2.71(7)$ \\
\hline & 3.2( & $2.04(1)$ & $0.6(5)$ & $2.36(6)$ & & \\
\hline Co30Sn_ & $2.1(2)$ & 2.07 (1) & & & $1.1(2)$ & $2.68(2)$ \\
\hline Co30Sn_reac & $2.2(2)$ & $2.04(1)$ & & & $1.5(2)$ & $2.63(1)$ \\
\hline
\end{tabular}

$S_{0}^{2}=0.82, \sigma^{2}=0.095 \AA^{2}, \Delta K=2-8, \Delta R=1-3.4$.

EXAFS oscillations were extracted using the Athena code and analysed using the Arthemis software (Ravel \& Newville, 2005). The Fourier transform of the EXAFS $\left[k^{2} \chi(k)\right]$ was performed in the $k$ range $\Delta k=2-8 \AA^{-1}$ and the fits were performed in the interval $\Delta R=1-3.4 \AA$. The local environment of the $\mathrm{Sn}$ atoms was determined using the phase shift and amplitude functions for $\mathrm{Sn}-\mathrm{O}$ calculated for $\mathrm{SnO}_{2}$. Using just the $\mathrm{Sn}-\mathrm{O}$ contribution was not enough to reproduce the experimental results. Fits were then performed using an Sn$\mathrm{O}-\mathrm{Sn}$ contribution or $\mathrm{Sn}-\mathrm{Co}$ contribution. The passive electron amplitude reduction factor $\left(S_{0}^{2}\right)$ was determined for the $\mathrm{SnO}_{2}$ standard and used as a fixed parameter in the fit of the data. For each contribution, a coordination number $\left(N_{i}\right)$ and a distance $\left(R_{i}\right)$ were fitted independently, while the mean square relative displacement $\left(\sigma_{i}^{2}\right)$ and the photoelectron energy origin correction $\left(\Delta E_{0}\right)$ were set to be the same for all paths.

Table 1 presents the best-fit results. All samples present an $\mathrm{Sn}-\mathrm{O}$ and $\mathrm{Sn}-\mathrm{Co}$ contribution after reduction. These observations are consistent with the $\mathrm{Sn}$ dopant existing as both an oxidic species, in particular on the alumina support, and a metallic species in an alloyed phase with cobalt. It is also possible that some tin oxide was present directly on the cobalt metal nanoparticles, as proposed earlier by Pouilloux et al.
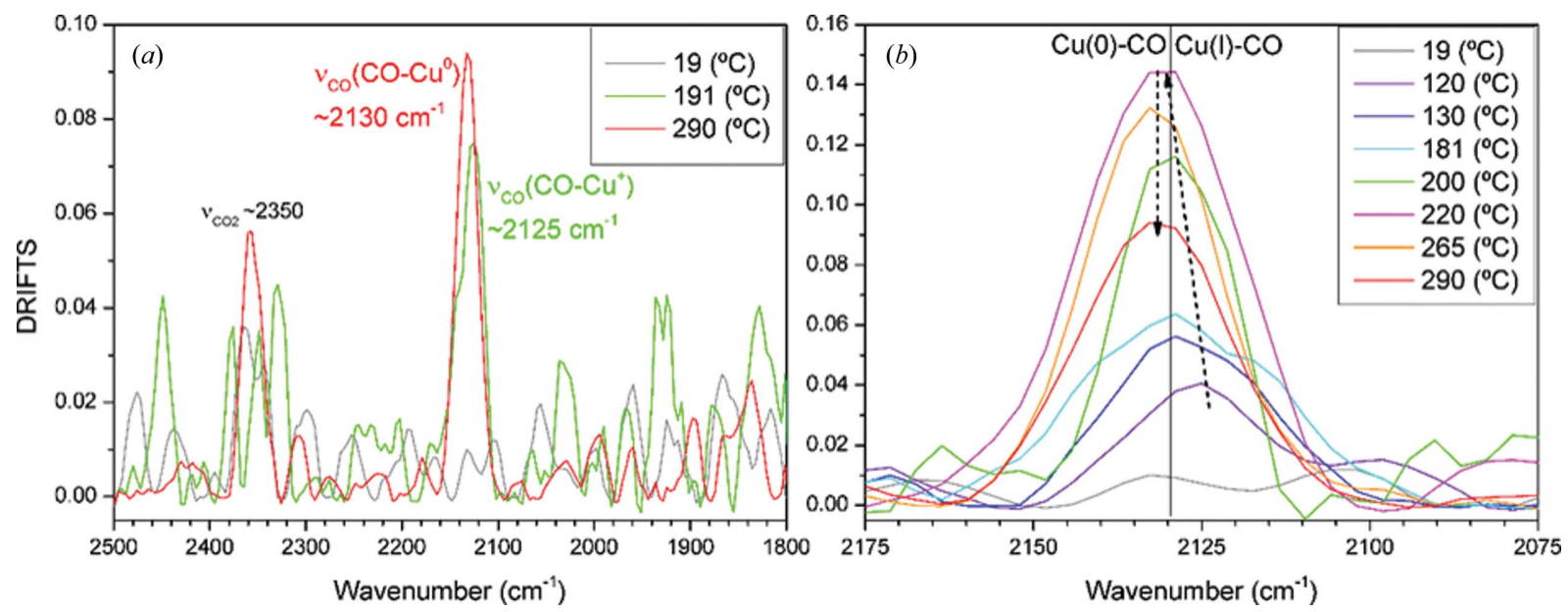

Figure 9

DRIFTS spectra of the $\mathrm{Cu} K$ edge of the sample $\left(1 \% \mathrm{Cu} / \mathrm{SiO}_{2}\right)$ during reduction under $\mathrm{CO}$. $(a)$ Selected spectra at different temperatures, showing the three steps of the evolution of copper carbonyl, and $(b)$ detail of the evolution of the carbonyl region during reduction. From 25 to $220^{\circ} \mathrm{C}$, the intensity increases while the centre moves to higher wavenumbers; from 220 to $300^{\circ} \mathrm{C}$, the intensity decreases without any shift in the signal. The IR signal-to-noise ratio is not good since the sample becomes dark during the reduction and $\mathrm{SiO}_{2}$ at room temperature was used as background. 
(2000) over similar catalysts used for the hydrogenation of fatty esters.

For the sample with the smallest amount of $\mathrm{Sn}$ (Sn:Co = $1: 120)$ under reaction, the $\mathrm{Sn}-\mathrm{Co}$ contribution was converted to an Sn-O-Sn contribution. For the sample with intermediate amounts of Sn (1:60), both models (with Sn-O-Sn or Sn-Co contribution) could reproduce the data. For the sample with the highest amount of Sn (1:30) only the model with an Sn-Co contribution could reproduce the data. Thus, we conclude that the Sn-Co interaction increases with the amount of Sn.

These observations suggest that, at low Sn loadings, most Sn was oxidized (the reaction products contain oxidizers such as water and $\mathrm{CO}_{2}$ ) and formed polymeric $\mathrm{SnO}_{x}$ species adsorbed on the alumina support or the cobalt phase. In contrast, metallic tin present in $\mathrm{Co}_{1-x} \mathrm{Sn}_{x}$ phases, with $x \ll 1$, prevails as the majority species at higher Sn loadings. These observations are consistent with earlier results showing that the sample with the highest amount of Sn was the most deactivated, since the active phase for syngas conversion to hydrocarbon is metallic cobalt (Paredes-Nunez et al., 2018).

The surface tension of tin $\left(675 \mathrm{~mJ} \mathrm{~m}^{-2}\right)$ is significantly lower than that of cobalt $\left(2550 \mathrm{~mJ} \mathrm{~m}^{-2}\right)$. Therefore, most of the $\mathrm{Sn}$ present in the $\mathrm{Co}_{1-x} \mathrm{Sn}_{x}$ alloy phase is likely to be present at surface sites with low coordination numbers of the corresponding $\mathrm{ca} \quad 8-10 \mathrm{~nm}$ diameter nanoparticles, i.e. at corners and steps. This is consistent with the observed low coordination number measured by EXAFS of between 1 and 2 (Table 1).

Fig. 10 presents a comparison for the IR data collected in a commercial SpectraTech reaction cell (Paredes-Nunez et al., 2018) and the data collected over the cell developed here. A detailed description of the band assignment obtained over these materials is reported elsewhere (Paredes-Nunez et al., 2018). Note that the X-ray fluorescence detector was partly in the path of the IR beam. Thus, the signal-to-noise ratio during the combined experiments was poor, although most of the main bands $\left(\mathrm{C}_{x} \mathrm{H}_{y}\right.$ and on-top $\left.\mathrm{CO}\right)$ could still be easily

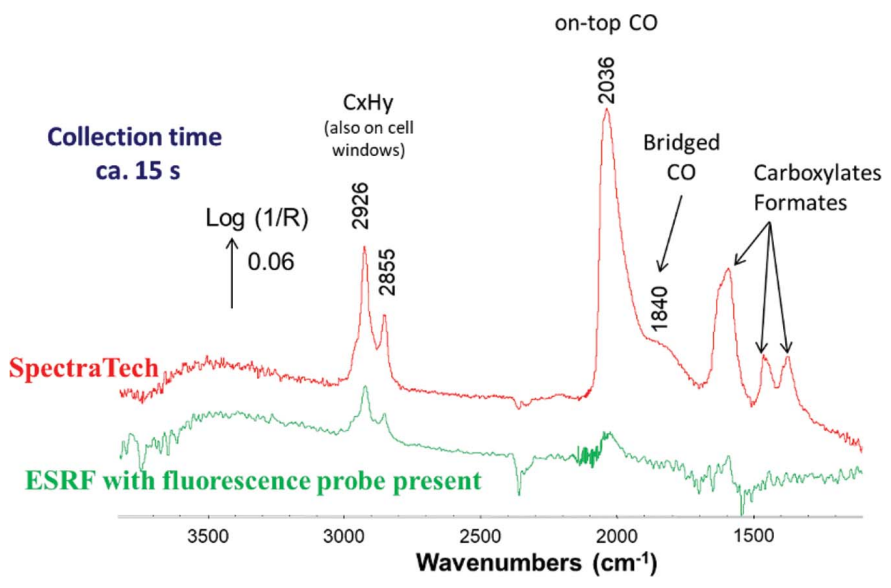

Figure 10

DRIFTS spectra over the sample $\mathrm{Sn} / \mathrm{Co}=1 / 120$ under reaction conditions at $220^{\circ} \mathrm{C}$ using a commercial SpectraTech cell (red) and the new cell developed here (green), the latter being used in the presence of a fluorescence detector. recognized. This aspect will have to be improved, but at the moment this experiment can be used as proof that the DRIFTS spectra recorded on the combined XAS-DRIFTS setup are consistent with those recorded on a commercial cell.

3.3. Spatially resolved XAS changes along the catalytic bed in $\mathrm{Cu}$ - and Ni-based catalysts for photocatalysis

Finally, we present here a photocatalysis experiment in which the changes in the analyte are followed by XAS along the catalytic bed under steady-state conditions. In this case, a UV light source was placed on top of the cell and the catalytic bed was monitored vertically to sample the different sample regions due to the light effect. A progression of changes can be detected from the top (gas inlet and sample illuminated by the light) to the bottom (gas outlet and sample under dark conditions). This case highlights two remarkable features of the cell: the compatibility of XAS with light excitation, and the possibility of simultaneously exploring all of the catalytic bed using a focused X-ray microbeam.

$\mathrm{Cu}$ and $\mathrm{Ni}$ XANES and EXAFS measurements were performed using the micro-XAS station on the BM23 beamline at the ESRF. An Si(111) double-crystal monochromator was used. Two Pt-coated mirrors, set to $6 \mathrm{mrad}$, were used for harmonic rejection and focusing. The focus spot was $3 \mu \mathrm{m} \times$ $3 \mu \mathrm{m}$ (FWHM) (Mathon et al., 2015). The experiment was performed in fluorescence mode using the same SDD detector described previously. A UV-grade $\mathrm{CaF}_{2}$ window (Crystran, $2 \mathrm{~mm}$ thickness) was mounted on top of the dome where the light source was placed, which was an optical fibre with a collimation head (model LLG211; LOT-Oriel) located at $2 \mathrm{~cm}$ from the sample. This light source $(350 \mathrm{~W}$; $\mathrm{Hg}$ lamp, LOTOriel) with a dichroic filter (280-400 nm; LOT-Oriel) was used to excite the sample exclusively with UV light (no visible nor IR light). Different catalytic regions along the catalytic bed were probed, since the cell was mounted on a vertical translation. Fig. 11 presents a diagram of the setup.

$\mathrm{TiO}_{2}$-based monometallic $\mathrm{Cu}$ and $\mathrm{Ni}$ and bimetallic $\mathrm{CuNi}$ catalysts were measured during methanol reforming in the presence and absence of UV light. A syringe pump was used to inject the liquid mixture (water-methanol) into an $\mathrm{He}$ carrier gas on a stainless steel line at $120^{\circ} \mathrm{C}$. A mass spectrometer (Pfeiffer) was connected to the cell outlet to ensure that the reaction took place. DRIFTS spectra can only be taken from the top part of the catalytic bed. However, DRIFTS was not recorded in this experiment since the spectrometer is not compatible with the micro-XAS station on BM23. This issue will be solved after the ESRF upgrade when high brilliance and a microbeam will be available and we will have enough space to accommodate the IR setup on the beamline.

Fig. 12 shows $\mathrm{Cu} K$-edge EXAFS spectra taken at specific positions of a $\mathrm{CuNi}$ bimetallic sample under three different experimental conditions. Sample positions are defined as the surface, the region of the sample affected by light (decay of $c a$ $99 \%$ of the intensity) and others defined by the distance from the surface. The 'dark' spectrum was measured in the presence of the reactive atmosphere but running the reaction under 

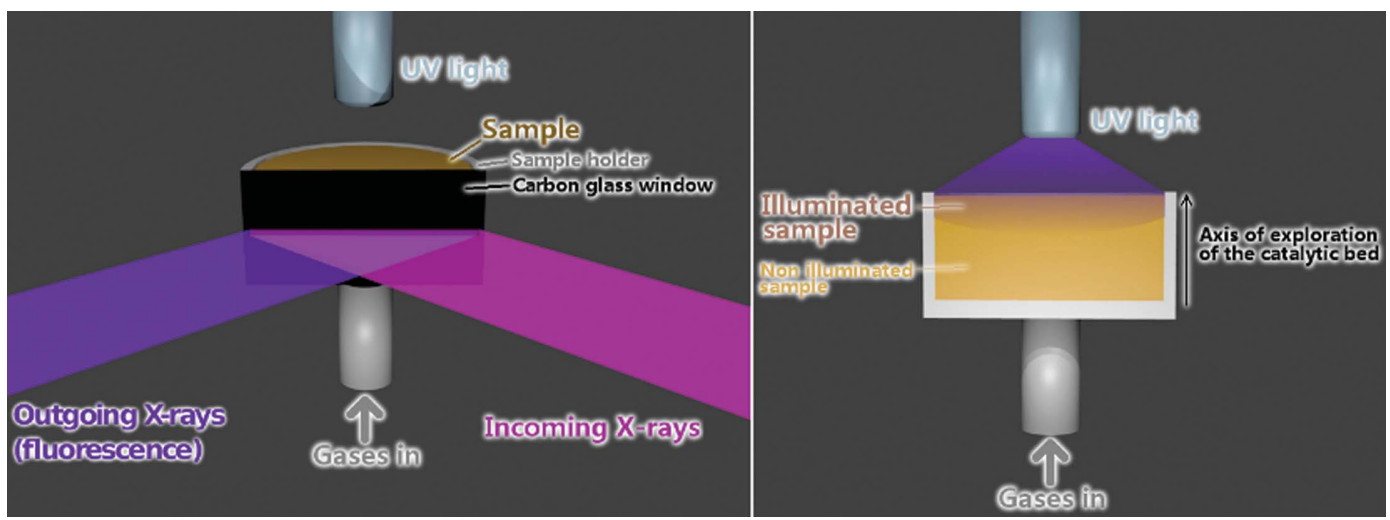

Figure 11

Details of the setup around the cell. (Left) The sample holder, the incoming/outgoing X-rays and UV light. (Right) The regions on the sample changing from gas+light (illuminated sample) to gas (no illuminated sample).

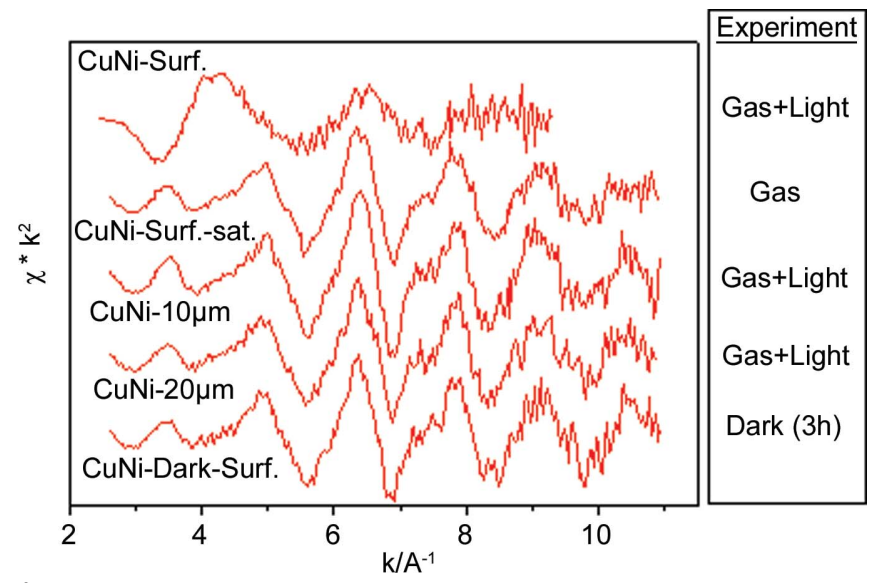

Figure 12

$\mathrm{Cu} K$-edge micro-EXAFS spectra of different positions of a $\mathrm{CuNi}-\mathrm{TiO}_{2}$ catalyst subjected to different experimental conditions.

dark conditions. The others were measured in a second, independent, experiment, where the catalyst was kept with the reactive atmosphere in the dark for $c a 1 \mathrm{~h}$ and subsequently exposed to the light source (conditions called 'gas' and 'gas+light' in the figure). The surface of the material is strongly sensitive to light and behaves differently from the rest of the material. In fact, Fig. 12 shows differences in the EXAFS oscillations due to copper oxidation progress from the 'gas' to 'gas+light' conditions. The numerical analysis of the surface EXAFS signal provided evidence of a mixture of (a dominant) $\mathrm{Cu}^{\mathrm{II}}$ and (a relatively minor) $\mathrm{Cu}^{0}$ species. Completing the analysis with the $\mathrm{Ni} K$-edge data, the contact between the reduced and oxidized non-noble metal phases was analysed for all the catalysts and shown to be the origin of the (catalytic) synergetic $\mathrm{Cu}-\mathrm{Ni}$ interaction in the bimetallic material. More details can be found elsewhere (Muñoz-Batista et al., 2018).

\section{Summary}

A new flexible cell for in situ combined DRIFTS-XAS-MS measurements has been developed and tested. Most catalysis experiments are performed using dilute systems where fluorescence measurements are necessary. Thus, using this cell, it is possible to measure in transmission or fluorescence modes according to the sample.

The best configuration (window materials and thickness) can be chosen depending on the specific requirements of the experiment. The detector position can also be changed, depending on the energy. The side window (carbon glass or Kapton) presents a lower absorption but a smaller solid angle, while the top window $\left(\mathrm{CaF}_{2}\right.$ or $\left.\mathrm{KBr}\right)$ increases the solid angle but presents a higher absorption and decreases the IR data quality. The sample can be heated to $600^{\circ} \mathrm{C}$ and the gas pressure increased to $5 \mathrm{bar}$, and the cell offers a low dead volume $\left(2.0 \mathrm{~cm}^{3}\right)$.

The cell can be independently aligned for XAS and DRIFTS, making it possible to probe the same volume of the sample with both techniques, and thus complementary information can be obtained from the two spectroscopies. In addition, it is also possible to illuminate the sample with a light probe for photocatalysis studies or Raman analysis. High data quality measurements on real catalysts (e.g. dilute metal loading, heavy and/or dark supports) are possible, to fulfil requirements that are rarely achieved at the same time for both XAS and DRIFT techniques. Nevertheless, the current results prove not only that an in situ multi-characterization study of catalysts is feasible, but also that this cell presents a wider range of applications than any other cell currently known for these kinds of study.

\section{Acknowledgements}

We would like to thank the ESRF staff who helped to make this work possible. A. Paredes-Nunez is acknowledged for helping carrying out the cobalt-based work.

\section{References}

Abe, H., Aquilanti, G., Boada, R., Bunker, B., Glatzel, P., Nachtegaal, M. \& Pascarelli, S. (2018). J. Synchrotron Rad. 25, 972-980.

Agostini, G., Meira, D., Monte, M., Vitoux, H., Iglesias-Juez, A., Fernández-García, M., Mathon, O., Meunier, F., Berruyer, G., 
Perrin, F., Pasternak, S., Mairs, T., Pascarelli, S. \& Gorges, B. (2018). J. Synchrotron Rad. 25, 1745-1752.

Armaroli, T., Bécue, T. \& Gautier, S. (2004). Oil Gas Sci. Technol. 59, 215-237.

Baer, D. R., Engelhard, M. H., Johnson, G. E., Laskin, J., Lai, J., Mueller, K., Munusamy, P., Thevuthasan, S., Wang, H., Washton, N., Elder, A., Baisch, B. L., Karakoti, A., Kuchibhatla, S. V. N. T. \& Moon, D. (2013). J. Vac. Sci. Technol. A, 31, 050820.

Beyer, K. A., Zhao, H., Borkiewicz, O. J., Newton, M. A., Chupas, P. J. \& Chapman, K. W. (2014). J. Appl. Cryst. 47, 95-101.

Cassinelli, W. H., Martins, L., Passos, A. R., Pulcinelli, S. H., Santilli, C. V., Rochet, A. \& Briois, V. (2014). Catal. Today, 229, 114-122.

Castillejos-López, E., Agostini, G., Di Michel, M., Iglesias-Juez, A. \& Bachiller-Baeza, B. (2017). ACS Catal. 7, 796-811.

Cotte, M., Fabris, T., Agostini, G., Motta Meira, D., De Viguerie, L. \& Solé, V. A. (2016). Anal. Chem. 88, 6154-6160.

Dandekar, A. \& Vannice, M. A. (1998). J. Catal. 178, 621-639.

Dou, J., Sun, Z., Opalade, A. A., Wang, N., Fu, W. \& Tao, F. (2017). Chem. Soc. Rev. 46, 2001-2027.

Frenkel, A. I., Hills, C. W. \& Nuzzo, R. G. (2001). J. Phys. Chem. B, 105, 12689-12703.

Friend, C. M. \& Xu, B. (2017). Acc. Chem. Res. 50, 517-521.

Gervasini, A., Manzoli, M., Martra, G., Ponti, A., Ravasio, N., Sordelli, L. \& Zaccheria, F. (2006). J. Phys. Chem. B, 110, 78517861.

Grunwaldt, J.-D., Caravati, M., Hannemann, S. \& Baiker, A. (2004). Phys. Chem. Chem. Phys. 6, 3037-3047.

Kim, J.-H., Tian, Z., Kim, M.-G. \& Kwon, S.-J. (2014). Surf. Interface Anal. 46, 289-292.

Kim, J. Y., Rodriguez, J. A., Hanson, J. C., Frenkel, A. I. \& Lee, P. L. (2003). J. Am. Chem. Soc. 125, 10684-10692.

Kuzmin, A. \& Chaboy, J. (2014). IUCrJ, 1, 571-589.

Kwak, J. H., Varga, T., Peden, C. H. F., Gao, F., Hanson, J. C. \& Szanyi, J. (2014). J. Catal. 314, 83-93.

Marchionni, V., Kambolis, A., Nachtegaal, M., Kröcher, O. \& Ferri, D. (2017). Catal. Struct. React. 3, 71-78.

Marinkovic, N. S., Wang, Q. \& Frenkel, A. I. (2011). J. Synchrotron Rad. 18, 447-455.

Mathon, O., Beteva, A., Borrel, J., Bugnazet, D., Gatla, S., Hino, R., Kantor, I., Mairs, T., Munoz, M., Pasternak, S., Perrin, F. \& Pascarelli, S. (2015). J. Synchrotron Rad. 22, 1548-1554.

Meunier, F. C. (2016). React. Chem. Eng. 1, 134-141.

Meunier, F. C., Goguet, A., Shekhtman, S., Rooney, D. \& Daly, H. (2008). Appl. Catal. Gen. 340, 196-202.

Meunier, F. C., Reid, D., Goguet, A., Shekhtman, S., Hardacre, C., Burch, R., Deng, W. \& Flytzani-Stephanopoulos, M. (2007). J. Catal. 247, 277-287.
Muddada, N. B., Olsbye, U., Caccialupi, L., Cavani, F., Leofanti, G., Gianolio, D., Bordiga, S. \& Lamberti, C. (2010). Phys. Chem. Chem. Phys. 12, 5605-5618.

Muñoz-Batista, M. J., Motta Meira, D., Colón, G., Kubacka, A. \& Fernández-García, M. (2018). Angew. Chem. Int. Ed. 57, 11991203.

Nagai, Y., Dohmae, K., Ikeda, Y., Takagi, N., Tanabe, T., Hara, N., Guilera, G., Pascarelli, S., Newton, M., Kuno, O., Jiang, H., Shinjoh, H. \& Matsumoto, S. (2008). Angew. Chem. Int. Ed. 47, 93039306.

Newton, M. A. (2009). Top. Catal. 52, 1410-1424.

Newton, M. A., Jyoti, B., Dent, A. J., Fiddy, S. G. \& Evans, J. (2004). Chem. Commun. pp. 2382-2383.

Newton, M. A., Dent, A. J., Fiddy, S. G., Jyoti, B. \& Evans, J. (2007). Catal. Today, 126, 64-72.

Neylon, M. K., Marshall, C. L. \& Kropf, A. J. (2002). J. Am. Chem. Soc. 124, 5457-5465.

Paredes-Nunez, A., Lorito, D., Burel, L., Motta-Meira, D., Agostini, G., Guilhaume, N., Schuurman, Y. \& Meunier, F. (2018). Angew. Chem. Int. Ed. 57, 547-550.

Pascarelli, S., Mathon, O., Mairs, T., Kantor, I., Agostini, G., Strohm, C., Pasternak, S., Perrin, F., Berruyer, G., Chappelet, P., Clavel, C. \& Dominguez, M. C. (2016). J. Synchrotron Rad. 23, 353-368.

Pascarelli, S., Neisius, T. \& De Panfilis, S. (1999). J. Synchrotron Rad. 6, 1044-1050.

Pouilloux, Y., Autin, F. \& Barrault, J. (2000). Catal. Today, 63, 87100.

Ravel, B. \& Newville, M. (2005). J. Synchrotron Rad. 12, 537-541.

Ritzkopf, I., Vukojević, S., Weidenthaler, C., Grunwaldt, J. D. \& Schüth, F. (2006). Appl. Catal. Gen. 302, 215-223.

Sato, A. G., Volanti, D. P., de Freitas, I. C., Longo, E. \& Bueno, J. M. C. (2012). Catal. Commun. 26, 122-126.

Simpson, B. H. \& Rodríguez-López, J. (2015). Anal. Methods, 7, 7029-7041.

Sirita, J., Phanichphant, S. \& Meunier, F. C. (2007). Anal. Chem. 79, 3912-3918.

Sun, Z., Liu, Q., Yao, T., Yan, W. \& Wei, S. (2015). Sci. China Mater. 58, 313-341.

Wang, X., Hanson, J. C., Frenkel, A. I., Kim, J. \& Rodriguez, J. A. (2004). J. Phys. Chem. B, 108, 13667-13673.

Xie, Y., Yin, Y., Zeng, S., Gao, M. \& Su, H. (2017). Catal. Commun. 99, 110-114.

Yao, S., Mudiyanselage, K., Xu, W., Johnston-Peck, A. C., Hanson, J. C., Wu, T., Stacchiola, D., Rodriguez, J. A., Zhao, H., Beyer, K. A., Chapman, K. W., Chupas, P. J., Martínez-Arias, A., Si, R., Bolin, T. B., Liu, W. \& Senanayake, S. D. (2014). ACS Catal. 4, 16501661. 